Supporting Information for

\title{
Dual Molecularly Imprinted Polymer-Based Plasmonic Immunosandwich Assay for the Specific and Sensitive Detection of Protein Biomarkers
}

Rongrong Xing, Yanrong Wen, Yueru Dong, Yijia Wang, Qi Zhang, and Zhen Liu*

State Key Laboratory of Analytical Chemistry for Life Science, School of Chemistry and Chemical

Engineering, Nanjing University, Nanjing 210023, China

* Corresponding author: zhenliu@nju.edu.cn

\section{Contents:}

- Supplementary Experimental Section

- Supplementary Figures

Figure S1 to Figure S13

- Supplementary Tables

Table S1 to Table S2 


\section{Supplementary Experimental Section}

Reagents and Materials. Horseradish peroxidase (HRP), bovine serum albumin (BSA), ribonuclease A (RNase A), ribonuclease B (RNase B), adenosine, deoxyadenosine, 2,4-difluoro-3formyl-phenylboronic acid (DFFPBA), trypsin, trifluoroacetic acid (TFA), sinapic acid (SA) and $\alpha$-cyano-4-hydroxycinnamic acid (CHCA) were obtained from Sigma-Aldrich (St. Louis, MO, USA). Neuron-specific enolase (NSE) was purchased from Abcam (Shanghai, China). Unglycated epitope peptides (HNFRNPSVL and SIEKIWARE) and glycated epitope peptides (HNFRNPSVLK-Fru and Fru-SIEKIWARE) with purity above 98\% were synthesized by Shanghai Top-Peptide Biotechnology (Shanghai, China). Aminopropyltriethoxysilane (APTES), 3ureidopropyltriethoxysilane (UPTES, ca 50\% v/v dissolved in methanol), isobutyltriethoxysilane (IBTES), tetraethyl orthosilicate (TEOS), p-aminothiophenol (PATP) and sodium cyanoborohydride $\left(\mathrm{NaBH}_{3} \mathrm{CN}\right)$ were purchased from $\mathrm{J} \& \mathrm{~K}$ scientific (Shanghai, China). Healthy human serum was purchased from Shuangliu Zhenglong Chemical and Biological Research Laboratory (Sichuan, China). Human serums from two small cell lung cancer (SCLC) patients were collected at the First People's Hospital of Hangzhou. ELISA kit for the detection of human NSE was purchased from CUSABIO (Wuhan, China). Ferric trichloride hexahydrate, 1,6hexanediamine, anhydrous sodium acetate, glycol, silver nitrate, ammonium bicarbonate, sodium dihydrogen phosphate, sodium hydroxide, sodium chloride, acetic acid (HAc) and anhydrous ethanol were purchased from Nanjing Reagent Company (Nanjing, China). Chloroauric acid $\left(\mathrm{HAuCl}_{4} \cdot 4 \mathrm{H}_{2} \mathrm{O}\right)$ was purchased from Shanghai Chemical Reagent Co. Ltd. (Shanghai, China). 
Methanol and acetonitrile (ACN) were purchased from Shanghai Macklin Biochemical (Shanghai, China). Trisodium citrate, ammonium hydroxide (28\%) and sulfuric acid (98\%) were purchased from Shanghai Lingfeng Chemical Reagent (Shanghai, China). Hydrogen peroxide $\left(\mathrm{H}_{2} \mathrm{O}_{2}, 30 \%\right)$ was purchased from Jinhuada Chemical Reagent (Guangzhou, China). Glass slides (75 mm $\times 25$ $\mathrm{mm}$ ) were purchased from the Shanghai Machinery Import and Export Corporation (Shanghai, China). All other reagents used were of analytical grade or higher. Water used in all the experiments was purified by a Milli-Q Advantage A10 water purification system (Millipore, Milford, MA, USA).

Instruments. Transmission electron microscopic (TEM) characterization was carried out on a JEM-1011 system (JEOL, Tokyo, Japan). Scanning electron microscopic (SEM) characterization was performed on a S-3400N II instrument (Hitachi, Tokyo, Japan). Ultraviolent spectral analysis was performed with a NanoDrop 2000/2000C spectrophotometer (Thermo Fisher, MA, USA). Particle size measurement was performed on a 90Plus dynamic light scattering (DLS) instrument (Brookhaven Instrument, Holtsville, NY, USA). Microplate reader analysis was carried out on a BioTek Synergy Mx microplate reader (Winooski, VT, USA). Matrix-assisted laser desorption/ionization time-of-flight mass spectrometric (MALDI-TOF MS) analysis was carried out on a 4800 plus MALDI TOF/TOF Analyzer (Applied Biosystems, Framingham, MA, USA) with a pulsed nitrogen laser operated at $337 \mathrm{~nm}$. The laser energy was adjusted to slightly above the threshold to obtain good resolution and signal-to-noise ratio $(\mathrm{S} / \mathrm{N})$. All mass spectra reported 
were obtained in the positive ion mode. The instrument was operated in linear mode for the detection of intact proteins and reflectron mode for the detection of peptides. External calibration was applied to the instrument before data collection. Protein standards (insulin: $\mathrm{M}+\mathrm{H}^{+}=5734$; ubiquitin: $\mathrm{M}+\mathrm{H}^{+}=8565$; cytochrome $\mathrm{C}: \mathrm{M}+\mathrm{H}^{+}=12,361$ and $\mathrm{M}+2 \mathrm{H}^{2+}=6181$ ) and peptide calibration standards (bradykinin fragment $\mathrm{M}+\mathrm{H}^{+}=757.3997$; angiotensin II: $\mathrm{M}+\mathrm{H}^{+}=1046.5423$; $\mathrm{P}_{14} \mathrm{R}: \mathrm{M}+\mathrm{H}^{+}=1533.8582 ; \mathrm{ACTH}$ fragment $18-39: \mathrm{M}+\mathrm{H}^{+}=2465.1989$; and insulin oxidized $\mathrm{B}$ : $\left.\mathrm{M}+\mathrm{H}^{+}=3494.6513\right)$ were used as external standards for the calibration for the detection of intact proteins and peptides, respectively. A typical spectrum was obtained by averaging 1,000 laser shots from 30 positions within the sample well. The accelerating voltage was $20 \mathrm{kV}$. The whole process was controlled by the 4000 Series Explorer Software V3.7.0. Data were processed using Data Explorer Software Version 3.7 (Applied Biosystems, Framingham, MA, USA). The matrixes for MALDI-TOF MS were $15 \mathrm{mg} / \mathrm{mL}$ CHCA (for peptide analysis) and $10 \mathrm{mg} / \mathrm{mL} \mathrm{SA}$ (for protein analysis) dissolved in 50\% ACN containing $0.1 \%(\mathrm{v} / \mathrm{v})$ TFA. Equivalent volumes $(1 \mu \mathrm{L})$ of the sample and matrix were sequentially dropped on the MALDI plate for MALDI-TOF MS analysis. Plasmonic detection was carried out on a Renishaw InVia Reflex confocal microscope (Renishaw, UK) equipped with a high-resolution grating with 1,800 grooves/cm, additional band-pass filter optics, and a CCD camera. Spectra were acquired using a $633 \mathrm{~nm}$ excitation laser line $(1 \mathrm{~s}$ integration time and 1 accumulation). The laser was focused onto the sample by using a $\times 50$ objective (N.A. 0.75), providing a spatial resolution of ca. $1 \mu \mathrm{m}^{2}$. All measurements were carried out using a He-Ne laser $\left(\lambda_{0}=633 \mathrm{~nm}\right.$; laser power at spot, $\left.17 \mathrm{~mW}\right)$. Wavelength calibration was performed by measuring silicon wafers through a $\times 50$ objective, evaluating the first-order phonon 
band of Si at $520 \mathrm{~cm}^{-1}$. Each spot was detected 20 times at different locations. Each spectrum was baseline corrected except for the noise test.

Preparation of magnetic nanoparticles (MNPs). The MNPs were synthesized according to a previously reported method. ${ }^{1}$ Briefly, $2.0 \mathrm{~g}$ of ferric trichloride hexahydrate, $13.0 \mathrm{~g}$ of 1 ,6hexanediamine and $4.0 \mathrm{~g}$ of anhydrous sodium acetate were mixed with $60 \mathrm{~mL}$ of glycol in a PTFElined autoclave and reacted at $198{ }^{\circ} \mathrm{C}$ for $6 \mathrm{~h}$. The resulting MNPs were washed with water and anhydrous ethanol three times each, and then dried at $50{ }^{\circ} \mathrm{C}$ in a vacuum overnight.

Preparation of boronic acid-functionalized $\mathrm{Fe}_{3} \mathrm{O}_{4} @ \mathrm{SiO}_{2} \mathrm{MNPs}$. The synthesis of boronic acidfunctionalized $\mathrm{Fe}_{3} \mathrm{O}_{4} @ \mathrm{SiO}_{2} \mathrm{MNPs}$ was comprised of three steps: 1) preparation of $\mathrm{Fe}_{3} \mathrm{O}_{4} @ \mathrm{SiO}_{2}$ MNPs, 2) preparation of amino-functionalized $\mathrm{Fe}_{3} \mathrm{O}_{4} @ \mathrm{SiO}_{2} \mathrm{MNPs}$, and 3) preparation of boronic acid-functionalized $\mathrm{Fe}_{3} \mathrm{O}_{4} @ \mathrm{SiO}_{2} \mathrm{MNPs}$.

For the preparation of $\mathrm{Fe}_{3} \mathrm{O}_{4} @ \mathrm{SiO}_{2} \mathrm{MNPs}, 200 \mathrm{~mL}$ of anhydrous ethanol, $7.5 \mathrm{~mL}$ of ammonium hydroxide $(28 \%)$ and $1.4 \mathrm{~mL}$ of TEOS were added into a 500 -mL three-neck roundbottomed flask, and then mechanically stirred at $300 \mathrm{rpm}$ for $20 \mathrm{~min}$ at $40^{\circ} \mathrm{C} .200 \mathrm{mg}$ of MNPs was dispersed into $20 \mathrm{~mL}$ of anhydrous ethanol by ultrasonication. The obtained suspension was added into the above flask, and then mechanically stirred at $300 \mathrm{rpm}$ for $20 \mathrm{~min}$ at $40{ }^{\circ} \mathrm{C}$. The resulting $\mathrm{Fe}_{3} \mathrm{O}_{4} @ \mathrm{SiO}_{2}$ MNPs were collected by a magnet, washed with water and anhydrous 
ethanol three times each, and then dried at $50{ }^{\circ} \mathrm{C}$ in a vacuum overnight.

For the preparation of amino-functionalized $\mathrm{Fe}_{3} \mathrm{O}_{4} @ \mathrm{SiO}_{2} \mathrm{MNPs}$, the obtained $\mathrm{Fe}_{3} \mathrm{O}_{4} @ \mathrm{SiO}_{2}$ MNPs were dispersed into $100 \mathrm{~mL}$ of anhydrous ethanol by ultrasonication in a 250 -mL three-neck round-bottomed flask. Then $3 \mathrm{~mL}$ of APTES was added into the flask, and mechanically stirred at $300 \mathrm{rpm}$ for $12 \mathrm{~h}$ at $80{ }^{\circ} \mathrm{C}$ in a water bath. The resulting amino-functionalized $\mathrm{Fe}_{3} \mathrm{O}_{4} @ \mathrm{SiO}_{2} \mathrm{MNPs}$ were collected by a magnet, washed with water and anhydrous ethanol three times each, and then dried at $50{ }^{\circ} \mathrm{C}$ in a vacuum overnight.

For the preparation of boronic acid-functionalized $\mathrm{Fe}_{3} \mathrm{O}_{4} @ \mathrm{SiO}_{2} \mathrm{MNPs}, 200 \mathrm{mg}$ of aminofunctionalized $\mathrm{Fe}_{3} \mathrm{O}_{4} @ \mathrm{SiO}_{2}$ MNPs were added to $80 \mathrm{~mL}$ of methanol containing $400 \mathrm{mg}$ of DFFPBA and $1 \%(\mathrm{w} / \mathrm{w}) \mathrm{NaBH}_{3} \mathrm{CN}$ in a $250-\mathrm{mL}$ three-neck round-bottomed flask, then the mixture was mechanically stirred at $300 \mathrm{rpm}$ for $24 \mathrm{~h}$ at room temperature. The obtained $\mathrm{Fe}_{3} \mathrm{O}_{4} @ \mathrm{SiO}_{2} @$ DFFPBA MNPs were collected by a magnet, washed with water and anhydrous ethanol three times each, and then dried at $50{ }^{\circ} \mathrm{C}$ in a vacuum overnight. The obtained $\mathrm{Fe}_{3} \mathrm{O}_{4} @ \mathrm{SiO}_{2} @$ DFFPBA MNPs were stored in a dry and sealed tube at room temperature for further use.

Preparation of epitope-imprinted MNPs. The epitope-imprinted MNPs were prepared according to our previously reported method, ${ }^{2}$ which was composed of three steps: 1) immobilization of glycated epitope, 2) oriented surface imprinting, and 3) removal of the glycated epitope.

For the immobilization of glycated epitope, $2 \mathrm{mg}$ of glycated epitope template was dissolved 
in $2 \mathrm{~mL}$ of ammonium bicarbonate buffer $(50 \mathrm{mM}$, pH 8.5) containing $500 \mathrm{mM} \mathrm{NaCl}$. Then $20 \mathrm{mg}$ of $\mathrm{Fe}_{3} \mathrm{O}_{4} @ \mathrm{SiO}_{2} @$ DFFPBA MNPs was dispersed in the resulting solution by ultrasonication, and then shaken at room temperature for $2 \mathrm{~h}$. The obtained glycated epitope-immobilized $\mathrm{Fe}_{3} \mathrm{O}_{4} @ \mathrm{SiO}_{2} @$ DFFPBA MNPs were magnetically collected and washed with ammonium bicarbonate buffer (50 mM, pH 8.5).

For oriented surface imprinting, the collected glycated epitope bound $\mathrm{Fe}_{3} \mathrm{O}_{4} @ \mathrm{SiO}_{2} @$ DFFPBA MNPs were dispersed into $150 \mathrm{~mL}$ of anhydrous ethanol containing 4.5 $\mathrm{mL}$ of ammonium hydroxide $(28 \%)$, and then $10 \mathrm{~mL}$ of water was added to resulting suspension and mechanically stirred for 5 min. Then different molar ratio of APTES, UPTES, IBTES and TEOS in $40 \mathrm{~mL}$ of anhydrous ethanol (the volume of APTES was kept at $20 \mu \mathrm{L}$ ) were added to the above suspension, and then mechanically stirred at $25{ }^{\circ} \mathrm{C}$ for a period time. In order to obtain the best recognition performance, the imprinting time was set at 50, 60, 70 or 80 min under different ratios of monomers. The obtained epitope-imprinted MNPs were collected by a magnet, washed with anhydrous ethanol three times, and then dried at $40{ }^{\circ} \mathrm{C}$ in a vacuum overnight.

For the removal of the glycated epitope, the obtained epitope-imprinted MNPs were dispersed into $2 \mathrm{~mL}$ of $\mathrm{ACN}: \mathrm{H}_{2} \mathrm{O}: \mathrm{HAc}=50: 49: 1(\mathrm{v} / \mathrm{v})$ and shaken for $20 \mathrm{~min}$ at room temperature. The above elution process was repeated three times. After removing the glycated epitope templates, the prepared epitope-imprinted MNPs were magnetically collected, washed with water and anhydrous ethanol three times each and then dried at $40{ }^{\circ} \mathrm{C}$ in a vacuum overnight. Non-imprinted MNPs were prepared using the same procedure except for the absence of glycated epitope templates. 
Selectivity of boronic acid-functionalized $\mathrm{Fe}_{3} \mathrm{O}_{4} @ \mathrm{SiO}_{2}$ MNPs. The selectivity of $\mathrm{Fe}_{3} \mathrm{O}_{4} @ \mathrm{SiO}_{2} @$ DFFPBA MNPs was investigated using adenosine and deoxyadenosine as test compounds. $2 \mathrm{mg}$ of $\mathrm{Fe}_{3} \mathrm{O}_{4} @ \mathrm{SiO}_{2} @$ DFFPBA MNPs was dispersed into $200 \mu \mathrm{L}$ of $1.0 \mathrm{mg} / \mathrm{mL}$ adenosine or deoxyadenosine in ammonium bicarbonate buffer $(50 \mathrm{mM}, \mathrm{pH} 8.5)$ containing 500 $\mathrm{mM} \mathrm{NaCl}$, then the mixture was shocked on a rotator at room temperature for $2 \mathrm{~h}$. The $\mathrm{Fe}_{3} \mathrm{O}_{4} @ \mathrm{SiO}_{2} @$ DFFPBA MNPs were magnetically collected and rinsed with $200 \mu \mathrm{L}$ of ammonium bicarbonate buffer (50 mM, pH 8.5) containing $500 \mathrm{mM} \mathrm{NaCl}$ and ammonium bicarbonate buffer (50 mM, pH 8.5) three times each. Finally, the $\mathrm{Fe}_{3} \mathrm{O}_{4} @ \mathrm{SiO}_{2} @$ DFFPBA MNPs were re-suspended and eluted in $20 \mu \mathrm{L}$ of 100 mM HAc solution for 1 h on a rotator. The $\mathrm{Fe}_{3} \mathrm{O}_{4} @ \mathrm{SiO}_{2} @ \mathrm{DFFPBA}$ MNPs were magnetically separated and the eluates were collected. The amounts of adenosine or deoxyadenosine bound by the $\mathrm{Fe}_{3} \mathrm{O}_{4} @ \mathrm{SiO}_{2} @$ DFFPBA MNPs were determined by measuring the amounts of adenosine or deoxyadenosine in the eluates in terms of UV absorbance at $260 \mathrm{~nm}$. The measurement was repeated three times. Subsequently, C- and N-terminal epitopes of NSE and corresponding glycated $\mathrm{C}$ - and N-terminal epitopes were selected as test compounds. The extraction procedure was the same as above except that the eluates were measured in terms of UV absorbance at $214 \mathrm{~nm}$. For control experiments, all the procedures were the same as described above except the absence of target analytes in the extraction buffer.

Optimization of monomer ratio and imprinting time. The monomer ratio and imprinting time 
were optimized according to the obtained imprinting factor (IF). $2.0 \mathrm{mg}$ of the epitope-imprinted and non-imprinted MNPs prepared by different proportions of monomers (APTES, UPTES, IBTES and TEOS) at different imprinting time were added to $1 \mathrm{~mL}$ of $0.1 \mathrm{mg} / \mathrm{mL}$ epitope dissolved in phosphate buffer (10 mM pH 7.4), respectively. After incubation at room temperature for $20 \mathrm{~min}$, the MNPs were magnetically collected and rinsed with $1 \mathrm{~mL}$ of phosphate buffer (10 mM, pH 7.4) three times. The MNPs were re-suspended and eluted in $50 \mu \mathrm{L}$ of ACN: $\mathrm{H}_{2} \mathrm{O}: \mathrm{HAc}=50: 49: 1(\mathrm{v} / \mathrm{v})$ for 10 min on a rotator. Finally, the MNPs were magnetically separated and the eluates were collected. The amount of epitope was determined by measuring the amount of epitope in the eluates in terms of UV absorbance at $214 \mathrm{~nm}$. The measurement was repeated three times. For control experiments, all the procedures were the same as described above except the absence of epitope in the extraction buffer.

Protein digestion by trypsin. The procedure for the tryptic digest of proteins used in the experiment was prepared as follows: $1.0 \mathrm{mg}$ of protein was dissolved in $1 \mathrm{~mL}$ of ammonium bicarbonate buffer $(100 \mathrm{mM}, \mathrm{pH} 8.5)$ in a $1.5 \mathrm{~mL}$-centrifugal tube, and heated in a water bath of $95{ }^{\circ} \mathrm{C}$ for $10 \mathrm{~min}$. After the protein solution was cooled to room temperature, $20 \mu \mathrm{L}$ of trypsin $(1.0$ $\mathrm{mg} / \mathrm{mL}$ ) was added to the above tube at $37{ }^{\circ} \mathrm{C}$ for $18 \mathrm{~h}$. Finally, the resulting mixture was heated again to $95{ }^{\circ} \mathrm{C}$ for $10 \mathrm{~min}$. The obtained protein digest solution was store at $-20^{\circ} \mathrm{C}$. 
Selectivity test of epitope-imprinted MNPs. The selectivity of the NSE C- and N-terminal epitope-imprinted MNPs in protein level was evaluated using NSE, RNsae A, BSA, RNase B and HRP. First, $0.1 \mathrm{mg} / \mathrm{mL}$ of each protein solution was separately prepared with phosphate buffer (10 $\mathrm{mM}, \mathrm{pH}$ 7.4). Then equivalent epitope-imprinted MNPs and non-imprinted MNPs (2 mg each) were added to $1 \mathrm{~mL}$ of the protein solutions in $1.5-\mathrm{mL}$ centrifugal tubes, respectively. The tubes were shaken on a rotator at room temperature for $20 \mathrm{~min}$. The MNPs were magnetically collected and rinsed with $1 \mathrm{~mL}$ of phosphate buffer $(10 \mathrm{mM}, \mathrm{pH} 7.4)$ three times. Second, the MNPs were re-suspended and eluted in $50 \mu \mathrm{L}$ of $\mathrm{ACN}: \mathrm{H}_{2} \mathrm{O}: \mathrm{HAc}=50: 49: 1(\mathrm{v} / \mathrm{v})$ for $10 \mathrm{~min}$ on a rotator. Finally, the MNPs were magnetically separated and the eluates were collected. The amount of proteins on the epitope-imprinted MNPs were determined by measuring the amount of proteins in the eluates in terms of UV absorbance at $214 \mathrm{~nm}$. The measurement was repeated three times. For control experiments, all the procedures were the same as described above except the absence of proteins in the extraction buffer. The eluates were also analyzed by MALDI-TOF MS.

The selectivity of the $\mathrm{C}$ - and N-terminal epitope-imprinted MNPs in the peptide level was evaluated with the mixtures of $\mathrm{C}$ - or N-terminal epitope and tryptic digest of HRP and BSA at mole ratios of 1:1:1. First, $1 \mathrm{~mL}$ of mixture solution of NSE C- or N-terminal epitope $(0.01 \mathrm{mM})$ and tryptic digest of HRP $(0.01 \mathrm{mM})$ and BSA $(0.01 \mathrm{mM})$ was prepared by phosphate buffer $(10 \mathrm{mM}$, $\mathrm{pH}$ 7.4). Then equivalent $\mathrm{C}$ - or N-terminal epitope-imprinted MNPs and corresponding nonimprinted MNPs (2 mg each) were added to $1 \mathrm{~mL}$ of the mixture solution in $1.5-\mathrm{mL}$ centrifugal tubes, respectively. The tubes were shaken on a rotator at room temperature for $20 \mathrm{~min}$. The MNPs were magnetically collected and rinsed with $1 \mathrm{~mL}$ of phosphate buffer $(10 \mathrm{mM}, \mathrm{pH} 7.4)$ three times. 
Second, the MNPs were re-suspended and eluted in $50 \mu \mathrm{L}$ of $\mathrm{ACN}: \mathrm{H}_{2} \mathrm{O}: \mathrm{HAc}=50: 49: 1$ (v/v) for 10 min on a rotator. Finally, the MNPs were magnetically separated and the eluates were collected. The eluates were analyzed by MALDI-TOF MS.

Preparation of gold nanoparticles (AuNPs). The AuNPs were synthesized as described by Ghosh et al. ${ }^{3}$ Briefly, $0.5 \mathrm{~mL}$ of $\mathrm{HAuCl}_{4}(1 \%$, w/v) was added in $50 \mathrm{~mL}$ of water, and brought to a boil with vigorous stirring, and then $0.424 \mathrm{~mL}$ of sodium citrate solution $(34 \mathrm{mM})$ was rapidly added to the above solution. After the color of the solution changed from colorless to black to purple, the solution was continued to reflux for $15 \mathrm{~min}$, then cooled down naturally to room temperature under constant stirring conditions. Finally, the resulting Au colloidal solution was fuchsia and stored at 4 ${ }^{\circ} \mathrm{C}$ before use.

Preparation of DFFPBA-functionalized AuNPs self-assembled monolayer (SAM)-coated glass substrates. The preparation route is shown in Figure S1a, which was comprised of three steps: 1) preparation of amino-functionalized glass substrates, 2) preparation of aminofunctionalized AuNPs SAM coated-glass substrates, and 3) preparation of boronic acidfunctionalized AuNPs SAM coated-glass substrates.

For the preparation of amino-functionalized glass substrates, a microscope glass slide $(75 \mathrm{~mm}$ $\times 25 \mathrm{~mm})$ was firstly cut into equal pieces $(25 \mathrm{~mm} \times 10 \mathrm{~mm})$ and then four small circles with a 
diameter of $4 \mathrm{~mm}$ were carved on the surface of each piece. The obtained uniformly sized substrates were immersed in piranha solution $\left(\mathrm{H}_{2} \mathrm{SO}_{4}: \mathrm{H}_{2} \mathrm{O}_{2}=7: 3, \mathrm{v} / \mathrm{v}\right)$ for $1 \mathrm{~h}$, and then rinsed repeatedly with water and anhydrous ethanol, and dried under a nitrogen stream. To functionalize with amino groups, the obtained substrates were soaked in 4\% (v/v) APTES solution dissolved in anhydrous ethanol for 9-12 $\mathrm{h}$ at room temperature. The resulting amino-functionalized glass substrates were rinsed repeatedly with anhydrous ethanol and water to remove the unreacted APTES from the surface of the glass substrates.

For the preparation of amino-functionalized AuNPs SAM coated-glass substrates, the aminomodified glass substrates were soaked in $5 \mathrm{~mL}$ of the Au colloidal solution for $12 \mathrm{~h}$ at room temperature, and then washed with water to remove the unbound AuNPs. The amino group of APTES could bind with AuNPs by electrostatic interaction, so a monolayer of AuNPs was formed on the surface of the glass substrates. The obtained AuNPs SAM coated-glass substrates were soaked in 4\% (v/v) APTES solution dissolved in anhydrous ethanol for $2 \mathrm{~h}$ at room temperature. The resulting amino-functionalized AuNPs SAM coated-glass substrates were rinsed repeatedly with anhydrous ethanol and water to remove the unreacted APTES.

For the preparation of boronic acid-functionalized AuNPs SAM coated-glass substrates, the amino-functionalized AuNPs SAM coated-glass substrates were soaked in $5 \mathrm{~mL}$ of methanol containing $5.0 \mathrm{mg} / \mathrm{mL}$ DFFPBA and $5.0 \mathrm{mg} / \mathrm{mL} \mathrm{NaBH}_{3} \mathrm{CN}$. After reaction at room temperature for $24 \mathrm{~h}$, the obtained DFFPBA-functionalized AuNPs SAM coated-glass slide was washed repeatedly with anhydrous ethanol and water. 
Preparation of silver nanoparticles (AgNPs). AgNPs were prepared as described by Lee and Meisel. ${ }^{4}$ In brief, $36 \mathrm{mg}$ of $\mathrm{AgNO}_{3}$ was dissolved in $200 \mathrm{~mL}$ of water in a 500-ml three-neck roundbottom flask, and then brought to boil under continuous stirring. $4 \mathrm{~mL}$ of $1 \%$ (w/v) trisodium citrate was added to the above flask. The mixture was boiled with stirring for about $40 \mathrm{~min}$ and then cooled down to room temperature naturally. The obtained AgNPs colloidal solution was stored at $4{ }^{\circ} \mathrm{C}$ before use.

Preparation of DFFPBA-functionalized Ag/PATP@SiO2 NPs. DFFPBA-functionalized Ag/PATP@ $\mathrm{SiO}_{2}$ NPs were prepared with slight modifications according to our previously reported method. ${ }^{26}$ The preparation route is shown in Figure S1b, which was comprised of three steps: 1) synthesis of Ag/PATP@ $\mathrm{SiO}_{2} \mathrm{NP}_{\mathrm{S}}, 2$ ) preparation of amino-modified Ag/PATP@ $\mathrm{SiO}_{2} \mathrm{NPs}$, and 3) preparation of boronic acid-functionalized Ag/PATP@ $\mathrm{SiO}_{2}$ NPs with DFFPBA.

For the synthesis of $\mathrm{Ag} / \mathrm{PATP} @ \mathrm{SiO}_{2} \mathrm{NP}_{\mathrm{S}}, 20 \mu \mathrm{L}$ of $1 \mathrm{mM}$ PATP dissolved in anhydrous ethanol was first added dropwise to $10 \mathrm{~mL}$ of $\mathrm{Ag}$ colloidal solution under rapid stirring for $40 \mathrm{~min}$. Then $40 \mathrm{~mL}$ of anhydrous ethanol and $0.7 \mathrm{~mL}$ of ammonia solution $(28 \%)$ were added to the above solution, respectively, and the mixture was stirred for $5 \mathrm{~min} .10 \mathrm{~mL}$ of $10 \mathrm{mM}$ TEOS dissolved in anhydrous ethanol was added to the above suspension, and the mixture was stirred at room temperature for 50 min. After that, the resultant Ag/PATP@ $\mathrm{SiO}_{2}$ NPs were centrifuged at 8,000 rpm for 10 min and washed with anhydrous ethanol three times. The Ag/PATP@ $\mathrm{SiO}_{2} \mathrm{NPs}_{\text {were }}$ 
redispersed in $10 \mathrm{~mL}$ of anhydrous ethanol.

For the preparation of amino-modified Ag/PATP@ $\mathrm{SiO}_{2} \mathrm{NPs}, 100 \mu \mathrm{L}$ of APTES was added to $10 \mathrm{~mL}$ of $\mathrm{Ag} / \mathrm{PATP} @ \mathrm{SiO}_{2} \mathrm{NPs}$ suspension dissolved in anhydrous ethanol, and the mixture was stirred at room temperature for $1 \mathrm{~h}$. The resulting amino-modified Ag/PATP@ $\mathrm{SiO}_{2} \mathrm{NPs}$ were centrifuged at 8,000 rpm for $10 \mathrm{~min}$, and then washed with anhydrous ethanol three times. The amino-modified Ag/PATP@ $\mathrm{SiO}_{2} \mathrm{NPs}$ were redispersed in $30 \mathrm{~mL}$ of methanol.

For the preparation of DFFPBA-functionalized Ag/PATP@ $\mathrm{SiO}_{2} \mathrm{NPs}, 300 \mu \mathrm{L}$ of $5 \mathrm{mg} / \mathrm{mL}$ DFFPBA and $300 \mu \mathrm{L}$ of $5 \mathrm{mg} / \mathrm{mL} \mathrm{NaBH}_{3} \mathrm{CN}$ were added into $30 \mathrm{~mL}$ of amino-modified Ag/PATP@ $\mathrm{SiO}_{2}$ NPs suspension. After reaction for $24 \mathrm{~h}$, the obtained DFFPBA-functionalized $\mathrm{Ag} / \mathrm{PATP} @ \mathrm{SiO}_{2} \mathrm{NPs}$ were centrifuged at 8,000 rpm for $10 \mathrm{~min}$, and then washed with anhydrous ethanol and water three times each. The DFFPBA-functionalized Ag/PATP@ $\mathrm{SiO}_{2} \mathrm{NPs}$ were redispersed in $9 \mathrm{~mL}$ of phosphate buffer $(10 \mathrm{mM}, \mathrm{pH} 7.4)$.

Optimization of extraction time and labeling time. The extraction time of NSE by C-terminal epitope-imprinted AuNPs SAM coated-glass slide was optimized. A volume of $5 \mu \mathrm{L}$ of $10 \mu \mathrm{g} / \mathrm{mL}$ NSE solution dissolved in phosphate buffer (10 mM, pH 7.4) was dropped on each spot of a Cterminal epitope-imprinted AuNPs SAM coated-glass slide and extracted in a humidity chamber for $5,10,15,20,25$ and $30 \mathrm{~min}$, respectively, followed by rinsing with phosphate buffer $(10 \mathrm{mM}$, $\mathrm{pH}$ 7.4) three times. Captured NSE was labeled with $5 \mu \mathrm{L}$ of N-terminal epitope-imprinted Ag/PATP@ $\mathrm{SiO}_{2}$ NPs for 15 min in a humidity chamber. The spots were washed with phosphate 
buffer $(10 \mathrm{mM}, \mathrm{pH}$ 7.4) three times, dried at room temperature and then detected by Raman spectrograph.

The labeling time of NSE by NSE N-terminal epitope-imprinted Ag/PATP@ $\mathrm{SiO}_{2} \mathrm{NPs}$ was optimized. $5 \mu \mathrm{L}$ of $10 \mu \mathrm{g} / \mathrm{mL}$ NSE solution dissolved in phosphate buffer (10 mM, pH 7.4) was dropped on each spot of a C-terminal epitope-imprinted AuNPs SAM coated-glass slide and extracted for $15 \mathrm{~min}$ in a humidity chamber, followed by rinsing with phosphate buffer (10 $\mathrm{mM}$, $\mathrm{pH}$ 7.4) three times. Captured NSE was labeled with $5 \mu \mathrm{L}$ of N-terminal epitope-imprinted Ag/PATP@ $\mathrm{SiO}_{2} \mathrm{NPs}$ in a humidity chamber for 5, 10, 15, 20, 25 and 30 min, respectively. The spots were washed with phosphate buffer $(10 \mathrm{mM}, \mathrm{pH} 7.4)$ three times, dried at room temperature and then detected by the Raman spectrograph.

\section{Selectivity of dual molecularly imprinted polymer-based plasmonic immunosandwich assay} (duMIP-PISA). The selectivity of duMIP-PISA was investigated with NSE, RNase A, BSA, RNase B and HRP. A volume of $5 \mu \mathrm{L}$ of protein solution $(10 \mu \mathrm{g} / \mathrm{mL})$ dissolved in phosphate buffer (10 mM, pH 7.4) was dropped on each spot of a C-terminal epitope-imprinted extraction array and extracted for $15 \mathrm{~min}$ in a humidity chamber, followed by rinsing with phosphate buffer (10 $\mathrm{mM}$, pH 7.4) three times. Captured protein was labeled with $5 \mu \mathrm{L}$ of $\mathrm{N}$-terminal epitope-imprinted Ag/PATP@SiO 2 NPs for 15 min in a humidity chamber. The spots were washed with phosphate buffer $(10 \mathrm{mM}, \mathrm{pH}$ 7.4) three times, dried at room temperature and then detected by Raman spectrograph. For dual non-imprinted polymer-based PISA(duNIP-PISA, both extraction array and 
labeling nanotags were non-imprinted), the processing procedure was the same.

Binding isotherm. $5 \mu \mathrm{L}$ of NSE solution at different concentrations dissolved in phosphate buffer (10 mM, pH 7.4) was dropped on each spot of a C-terminal epitope-imprinted AuNPs SAM coatedglass slide and extracted for 15 min in a humidity chamber, followed by rinsing with phosphate buffer (10 mM, pH 7.4) three times. Captured NSE was labeled with $5 \mu \mathrm{L}$ of N-terminal epitopeimprinted Ag/PATP@ $\mathrm{SiO}_{2}$ NPs for 15 min in a humidity chamber. The spots were washed with phosphate buffer $(10 \mathrm{mM}, \mathrm{pH} 7.4)$ three times, dried at room temperature and then detected by Raman spectrograph. For duNIP-PISA, the processing procedure was the same. Binding isotherms were measured by plot the Raman intensity against logarithmic concentration according to logistic curve fitting.

Determination of NSE in human serum. To demonstrate the potential for real sample application, the concentrations of NSE in serums from a healthy human and two SCLC patients were determined. Briefly, different amounts of NSE were added to the serum samples, making the spiked concentrations to be 5, 10, 50 and $100 \mathrm{ng} / \mathrm{mL}$ in healthy human serum, 100, 200, 1000 and 2000 $\mathrm{ng} / \mathrm{mL}$ in patient-1 serum, and $25,50,250$ and $500 \mathrm{ng} / \mathrm{mL}$ in patient-2 serum, respectively. A volume of $5 \mu \mathrm{L}$ of the spiked or unspiked serum samples was dropped on each spot of an imprinted extraction array and extracted for $15 \mathrm{~min}$ in a humidity chamber, followed by rinsing with 
phosphate buffer (10 mM, pH 7.4) three times. Captured protein was labeled with $5 \mu \mathrm{L}$ of NSE Nterminal epitope-imprinted Ag/PATP@ $\mathrm{SiO}_{2} \mathrm{NPs}$ for 15 min in a humidity chamber. The spots were washed with phosphate buffer $(10 \mathrm{mM}, \mathrm{pH} 7.4)$ three times, dried at room temperature and then detected by the Raman spectrograph.

ELISA of NSE. ELISA of serum NSE was carried out using a commercial kit obtained from CUSABIO (Wuhan, China), including a microplate coated with anti-NSE antibody, reagents and standards. The procedure was the same as the instruction. Briefly, standards and samples were pipetted into the wells and. NSE present in the samples was bound by the immobilized antibody. After removing unbound substances, a biotin-conjugated antibody specific for NSE was added to the wells. After washing, avidin conjugated HRP was added to the wells. Following a wash step to remove unbound avidin-enzyme reagent, a substrate solution of 3,3',5,5'-tetramethylbenzidine dihydrochloride (TMB) was added to the wells. TMB was converted to a blue color by peroxidase catalysis and converted to a final yellow color under acidic action, and color developed in proportion to the amount of NSE bound in the initial step. After the color development was stopped, the absorbance (OD value) was measured at $450 \mathrm{~nm}$ using a microplate reader to calculate the sample concentration. 


\section{References}

(1) Wang, L. Y.; Bao, J.; Wang, L.; Zhang, F.; Li, Y. D. One-Pot Synthesis and Bioapplication of Amine-Functionalized Magnetite Nanoparticles and Hollow Nanospheres. Chem. Eur. J. 2006, 12, 6341-6347.

(2) Xing, R. R.; Ma, Y. Y.; Wang, Y. J.; Wen, Y. R.; Liu, Z. Specific Recognition of Proteins and Peptides via Controllable Oriented Surface Imprinting of Boronate Affinity-Anchored Epitopes. Chem. Sci. 2019, 10, 1831-1835.

(3) Ghosh, D.; Sarkar, D.; Girigoswami, A.; Chattopadhyay, N. A Fully Standardized Method of Synthesis of Gold Nanoparticles of Desired Dimension in the Range 15 nm-60 nm. J. Nanosci. Nanotechnol. 2011, 11, 1141-1146.

(4) Lee, P. C.; Meisel, D. Adsorption and Surface-Enhanced Raman of Dyes on Silver and Gold Sols. J. Phys. Chem. 1982, 86, 3391-3395. 


\section{Supplementary Figures}

(a)

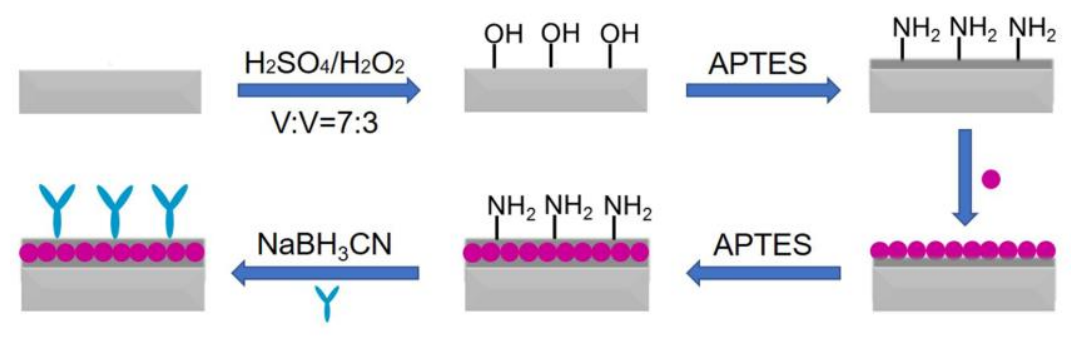

(b)

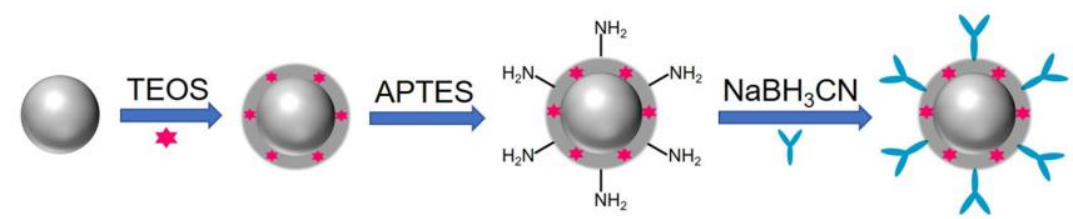

$$
\text { AgNPs - AuNPs * Raman reporter Y Boronic acid Glass slide }
$$

Figure S1. Schematic of the synthesis route of (a) boronic acid-functionalized AuNPs SAM coated-glass substrates and (b) boronic acid-functionalized Ag/PATP@ $\mathrm{SiO}_{2} \mathrm{NPs}$. 


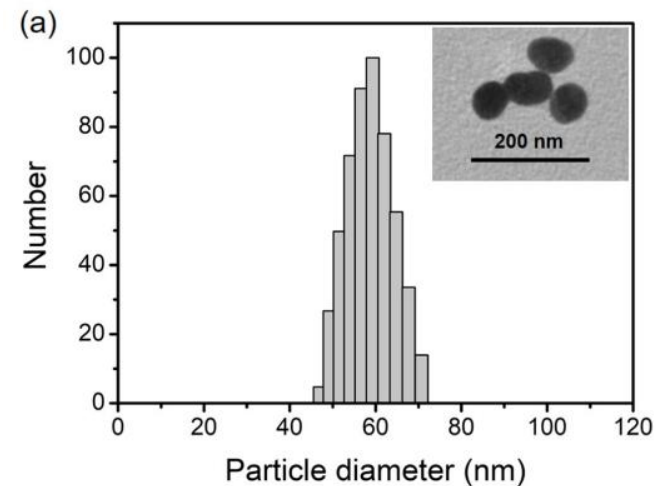

(b)
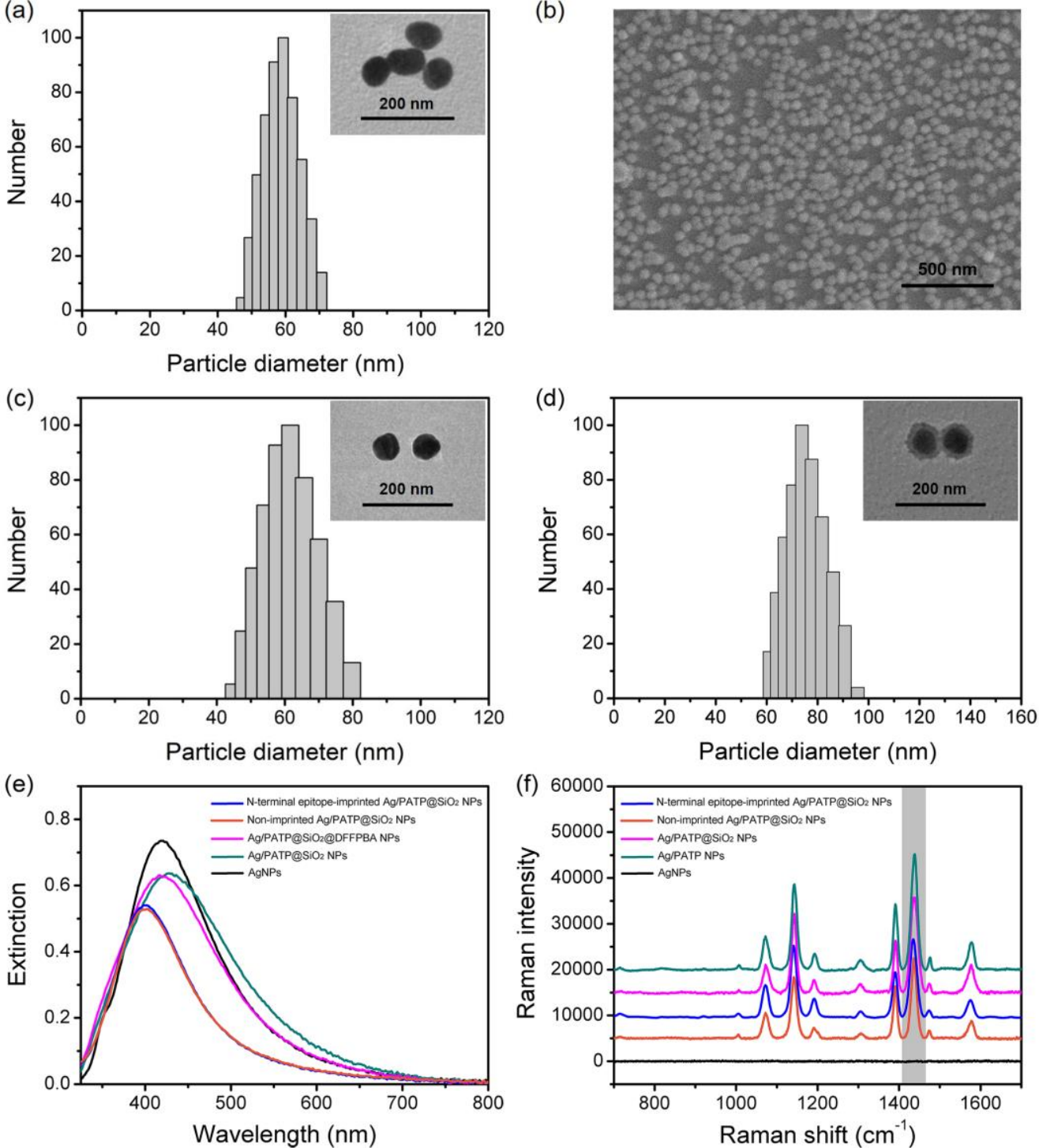

Figure S2. (a) DLS characterization of AuNPs. Insert: TEM image of AuNPs. (b) SEM characterization of a C-terminal epitope-imprinted AuNPs SAM coated-glass substrate. (c) DLS characterization of AgNPs. Inset: TEM image of AgNPs. (d) DLS characterization of N-terminal epitope-imprinted Ag/PATP@ $\mathrm{SiO}_{2}$ NPs. Inset: TEM image of N-terminal epitope-imprinted Ag/PATP@SiO2 NPs. (e) UV-vis extinction spectra of AgNPs, Ag/PATP@ $\mathrm{SiO}_{2}$ NPs, Ag/PATP@SiO $@$ DFFPBA NPs, N-terminal epitope-imprinted and non-imprinted Ag/PATP@SiO 2 NPs. (f) Raman spectra of AgNPs, Ag/PATP NPs, Ag/PATP@SiO 2 NPs, Nterminal epitope-imprinted and non-imprinted Ag/PATP@ $\mathrm{SiO}_{2} \mathrm{NPs}$. 
(a)

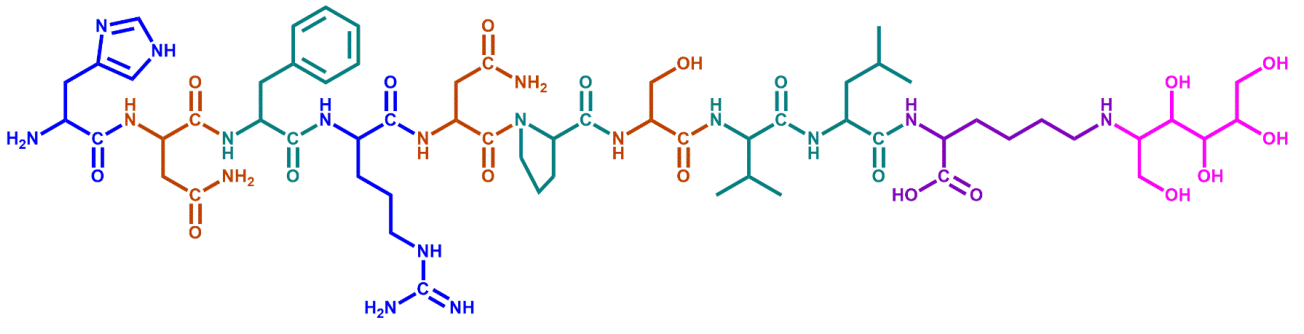

(b)

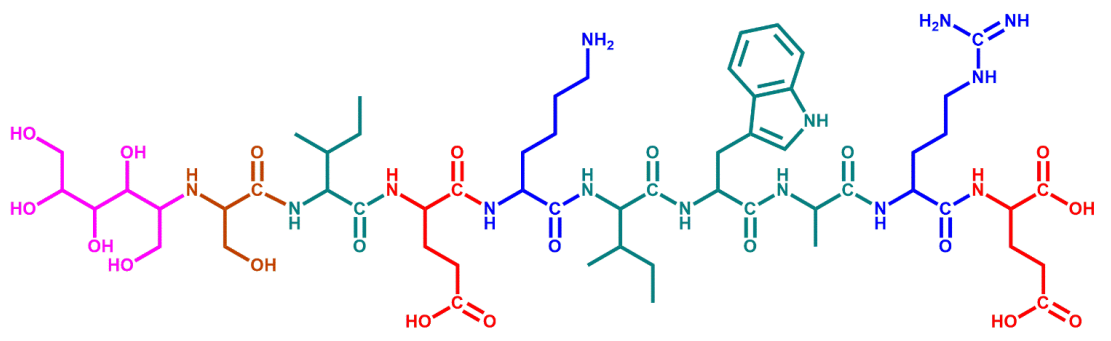

Figure S3. The structures of glycated epitopes of NSE. (a) glycated C-terminal epitope, and (b) glycated N-terminal epitope. 

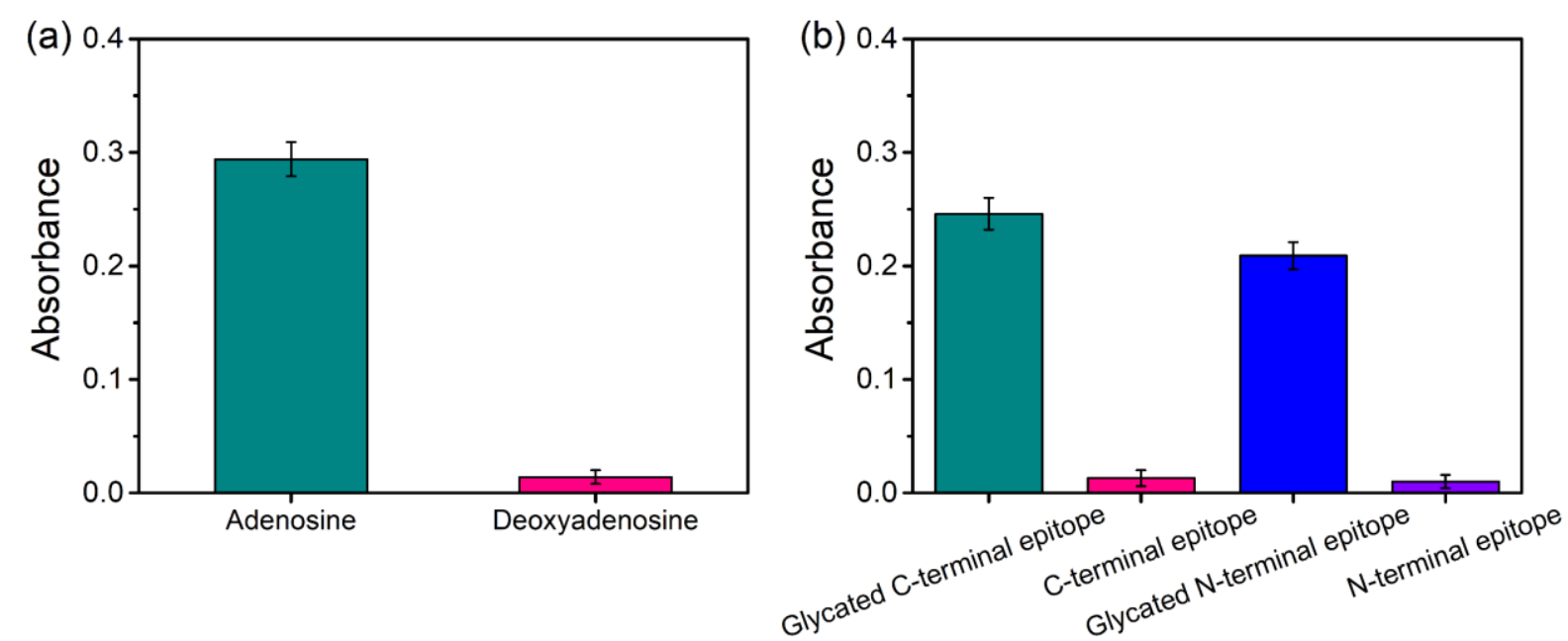

Figure S4. Comparison of the amounts of different analytes captured by $\mathrm{Fe}_{3} \mathrm{O}_{4} @ \mathrm{SiO}_{2} @ \mathrm{DFFPBA}$ MNPs. Samples: (a) adenosine and deoxyadenosine, and (b) non-glycated and glycated C- and Nterminal epitopes of NSE (1.0 $\mathrm{mg} / \mathrm{mL}$ each) dissolved in the binding buffer. Binding buffer: ammonium bicarbonate $(50 \mathrm{mM}, \mathrm{pH} 8.5)$ containing $500 \mathrm{mM} \mathrm{NaCl}$; Elution solution: $100 \mathrm{mM}$ HAc. The error bars represent the standard deviation for three parallel experiments. 

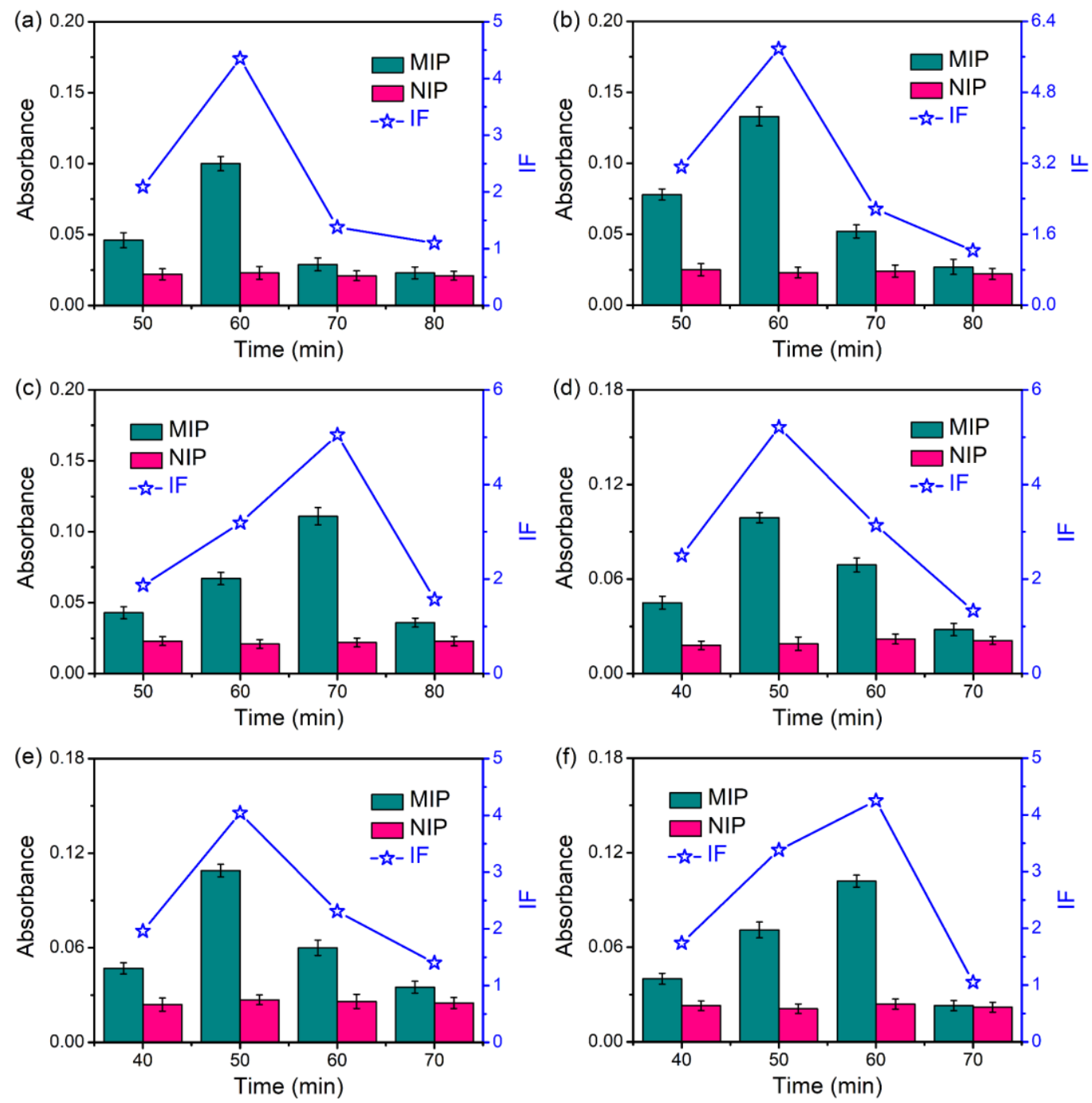

Figure S5. The optimization of monomer ratio and imprinting time of $\mathrm{C}$ - and $\mathrm{N}$-terminal epitopeimprinted MNPs. C-terminal epitope-imprinted MNPs and non-imprinted MNPs prepared with the ratio of APTES/UPTES/IBTES/TEOS at (a) 10:10:20:60, (b) 10:20:20:50, and (c) 10:10:30:50 under different imprinting time; N-terminal epitope-imprinted MNPs and non-imprinted MNPs prepared with the ratio of APTES/UPTES/IBTES/TEOS at (d) 10:10:20:60, (e) 10:20:20:50, and (f) 10:10:30:50 under different imprinting time. The error bars represent the standard deviation for three parallel experiments. 

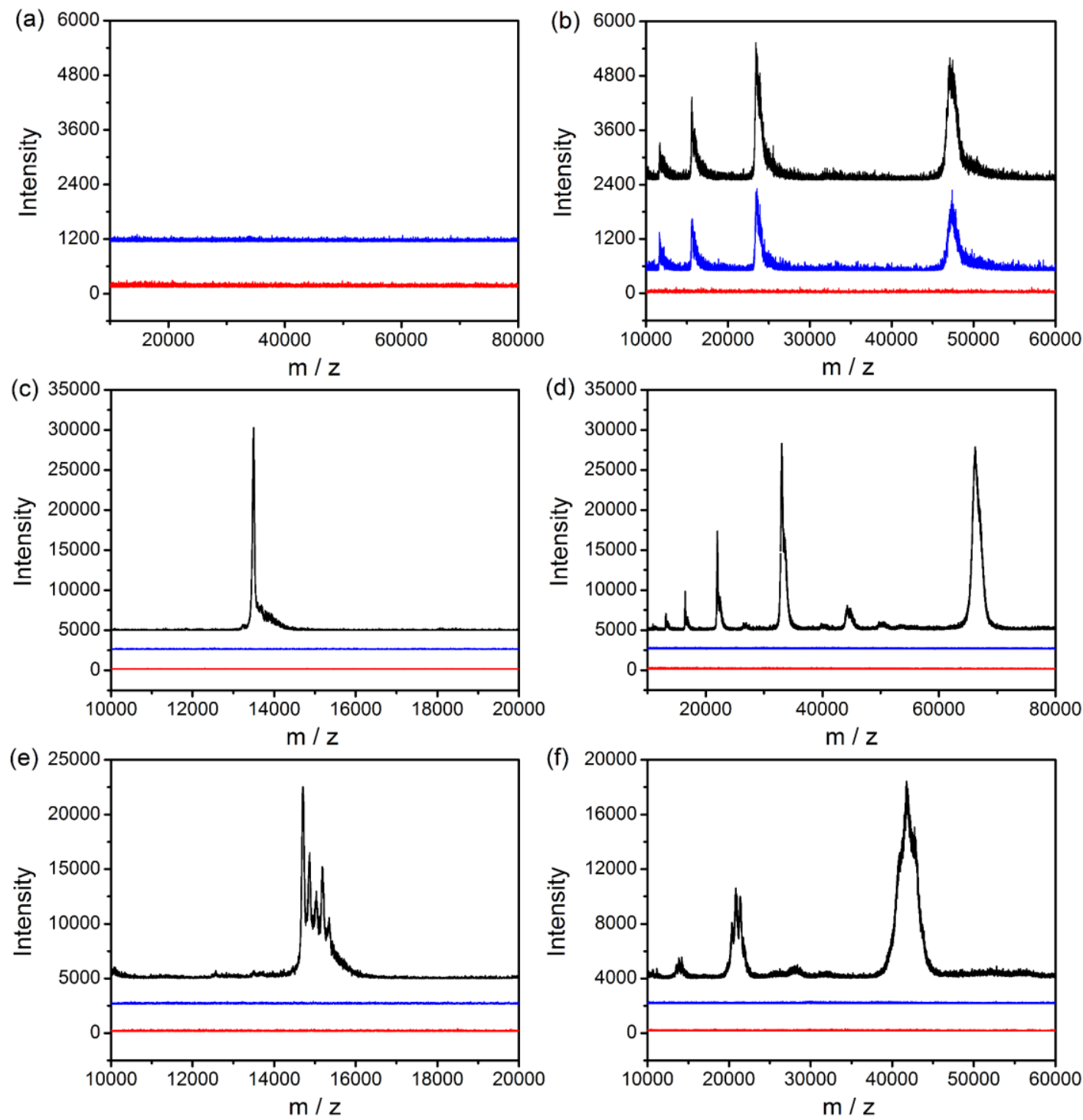

Figure S6. MALDI-TOF MS spectra of direct analysis of proteins (black line) and protein extracted by C-terminal epitope-imprinted MNPs prepared under optimized conditions (blue line) and corresponding non-imprinted MNPs (red line) from different samples. Samples: binding buffer (control) (a); $0.1 \mathrm{mg} / \mathrm{mL}$ protein dissolved in binding buffer (b-f): b) NSE, c) RNase A, d) BSA, e) RNase B and f) HRP). Binding buffer: phosphate buffer (10 mM, pH 7.4); Elution solution: $\mathrm{ACN}: \mathrm{H}_{2} \mathrm{O}: \mathrm{HAc}=50: 49: 1(\mathrm{v} / \mathrm{v})$. 

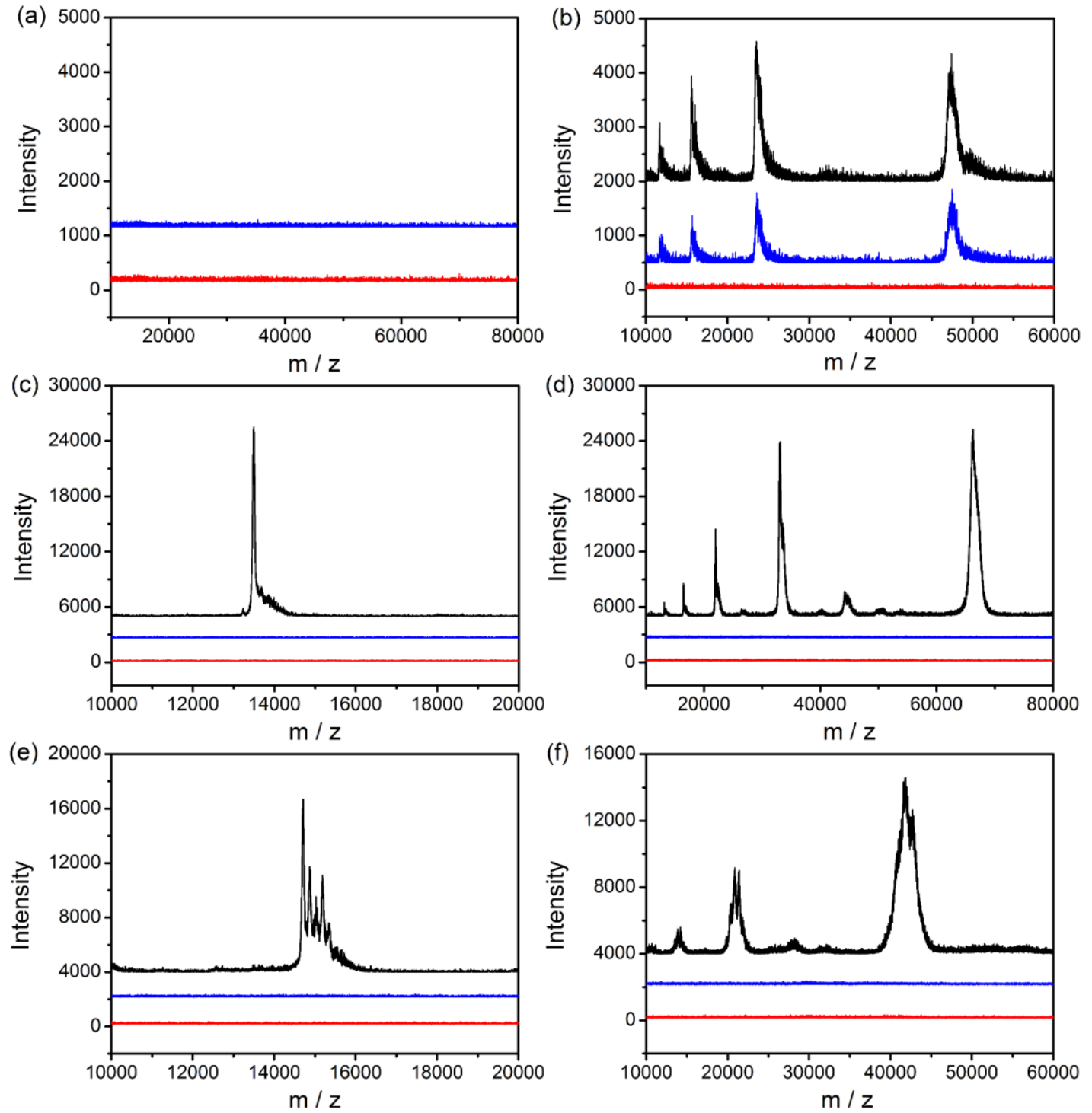

Figure S7. MALDI-TOF MS spectra of direct analysis of proteins (black line) and proteins extracted by N-terminal epitope-imprinted MNPs prepared under optimized conditions (blue line) and corresponding non-imprinted MNPs (red line) from different samples. Samples: binding buffer (control) (a); $0.1 \mathrm{mg} / \mathrm{mL}$ protein dissolved in binding buffer (b-f): b) NSE, c) RNase A, d) BSA, e) RNase B and f) HRP). Binding buffer: phosphate buffer (10 mM, pH 7.4); Elution solution: $\mathrm{ACN}: \mathrm{H}_{2} \mathrm{O}: \mathrm{HAc}=50: 49: 1(\mathrm{v} / \mathrm{v})$. 

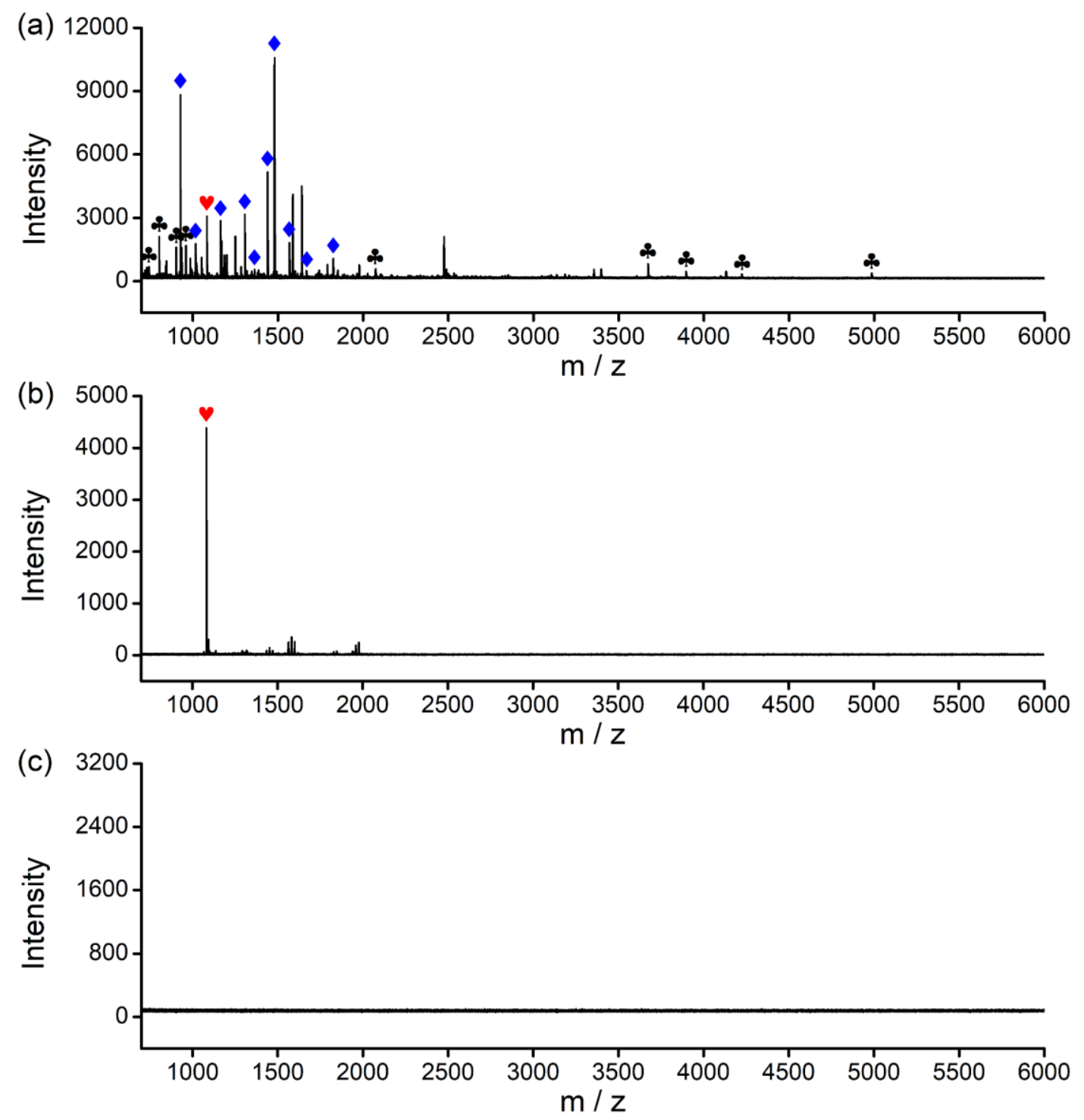

Figure S8. MALDI-TOF MS spectra for the analysis of the mixtures of the C-terminal epitope of NSE and tryptic digests of HRP and BSA with the mole ratio 1:1:1. (a) direct analysis; (b) analysis after extracted by C-terminal epitope-imprinted MNPs; (c) analysis after extracted by nonimprinted MNPs. ( $\bullet$ :C-terminal epitope of NSE; : peptides from tryptic digest of BSA; peptides from tryptic digest of HRP). 

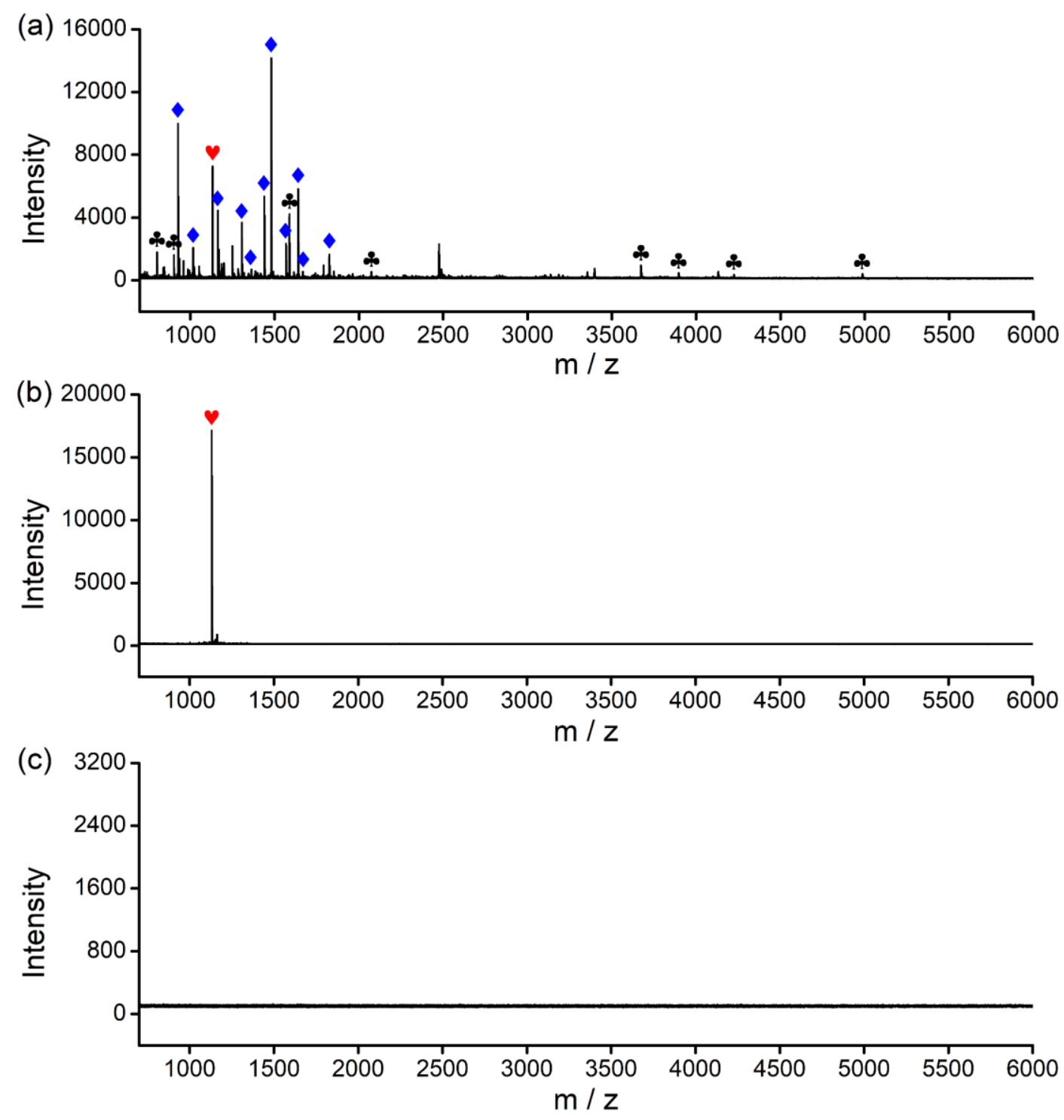

Figure S9. MALDI-TOF MS spectra for the analysis of the mixtures of the N-terminal epitope of NSE and tryptic digests of HRP and BSA with the mole ratio 1:1:1. (a) direct analysis; (b) analysis after extracted by N-terminal epitope-imprinted MNPs; (c) analysis after extracted by nonimprinted MNPs. ( $\vee$ : N-terminal epitope of NSE; $\$$ : peptides from tryptic digest of BSA; peptides from tryptic digest of HRP). 

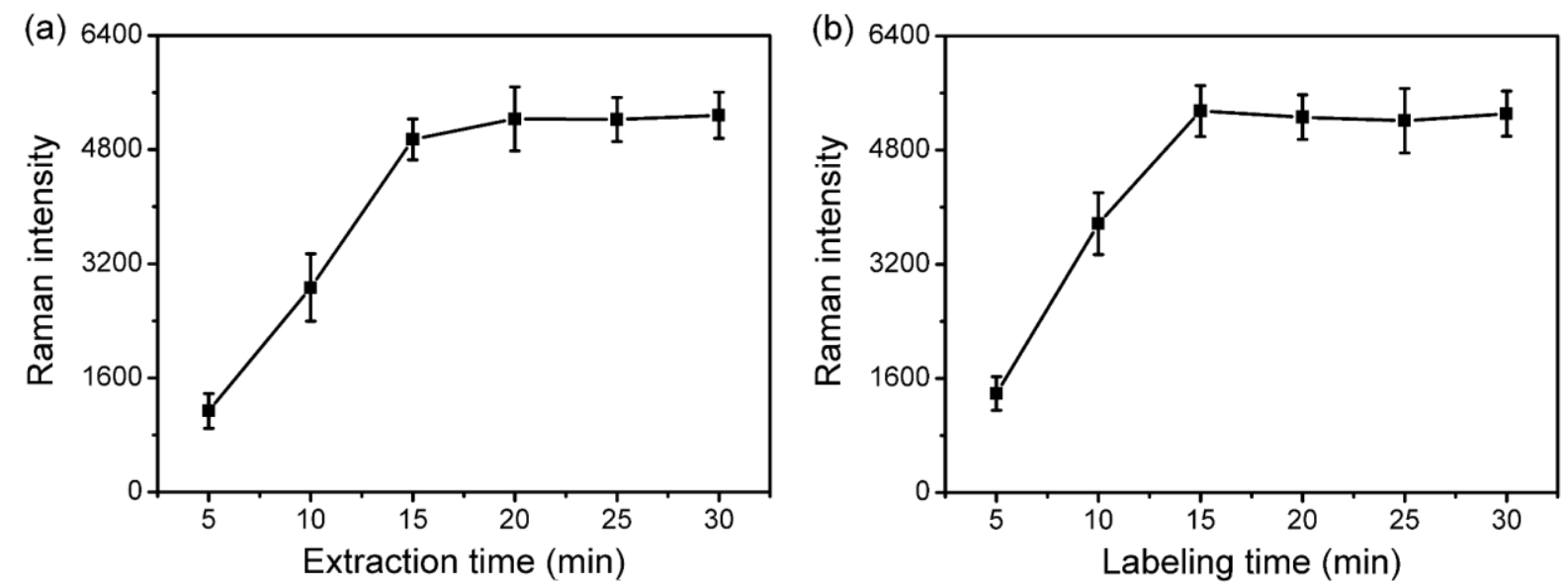

Figure S10. Dependence of the Raman intensity for NSE on (a) the extraction time of C-terminal epitope-imprinted AuNPs SAM coated-glass substrates, and (b) the labeling time of N-terminal epitope-imprinted Ag/PATP@ $\mathrm{SiO}_{2}$ NPs. Sample: $10 \mu \mathrm{g} / \mathrm{mL}$ NSE dissolved in phosphate buffer (10 mM, pH 7.4). The error bars represent the standard deviation for three parallel experiments. 

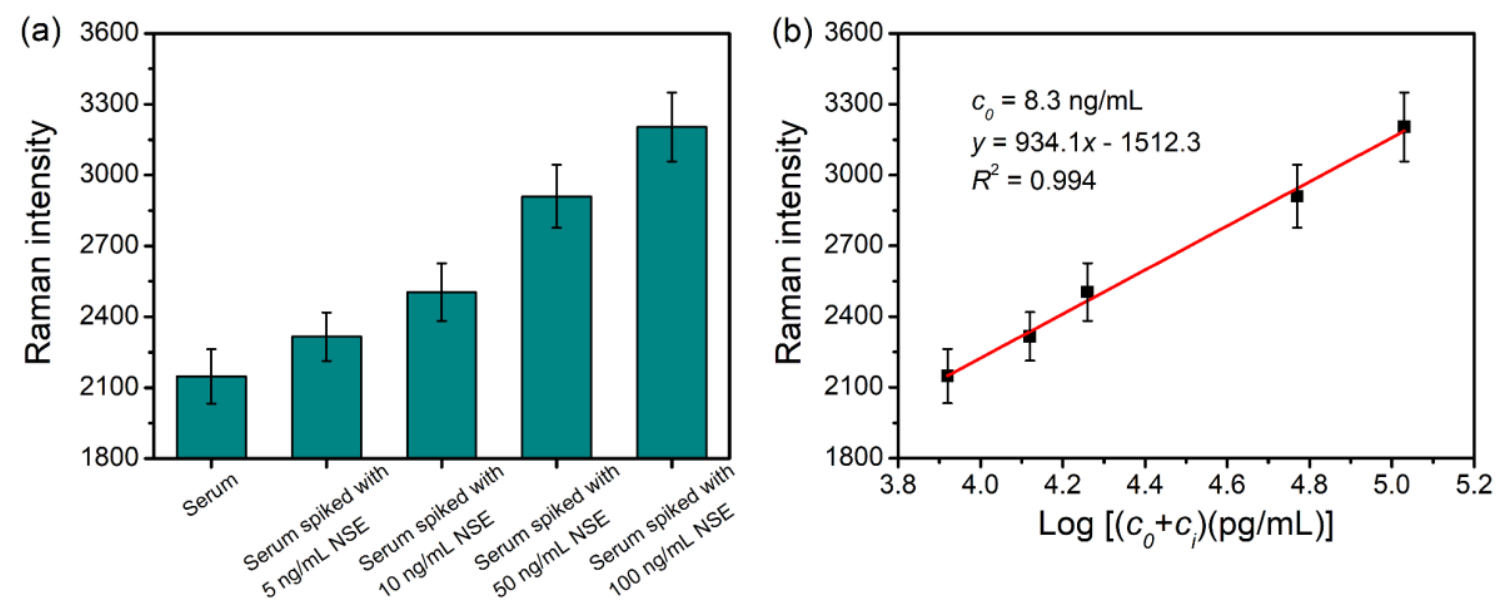

Figure S11. (a) Raman intensity for healthy human serum spiked with different concentrations of NSE, and (b) linear relationship between the Raman intensity and the logarithmic value of the total concentration of NSE in the sample $\left(\log \left[\left(c_{0}+c_{\mathrm{i}}\right)(\mathrm{pg} / \mathrm{mL})\right]\right)$, where $c_{0}$ was calculated according to the linear equation obtained with standard solutions by assuming that the matrix effect was eliminated by the duMIP-PISA. The error bars represent the standard deviation for three parallel experiments. 

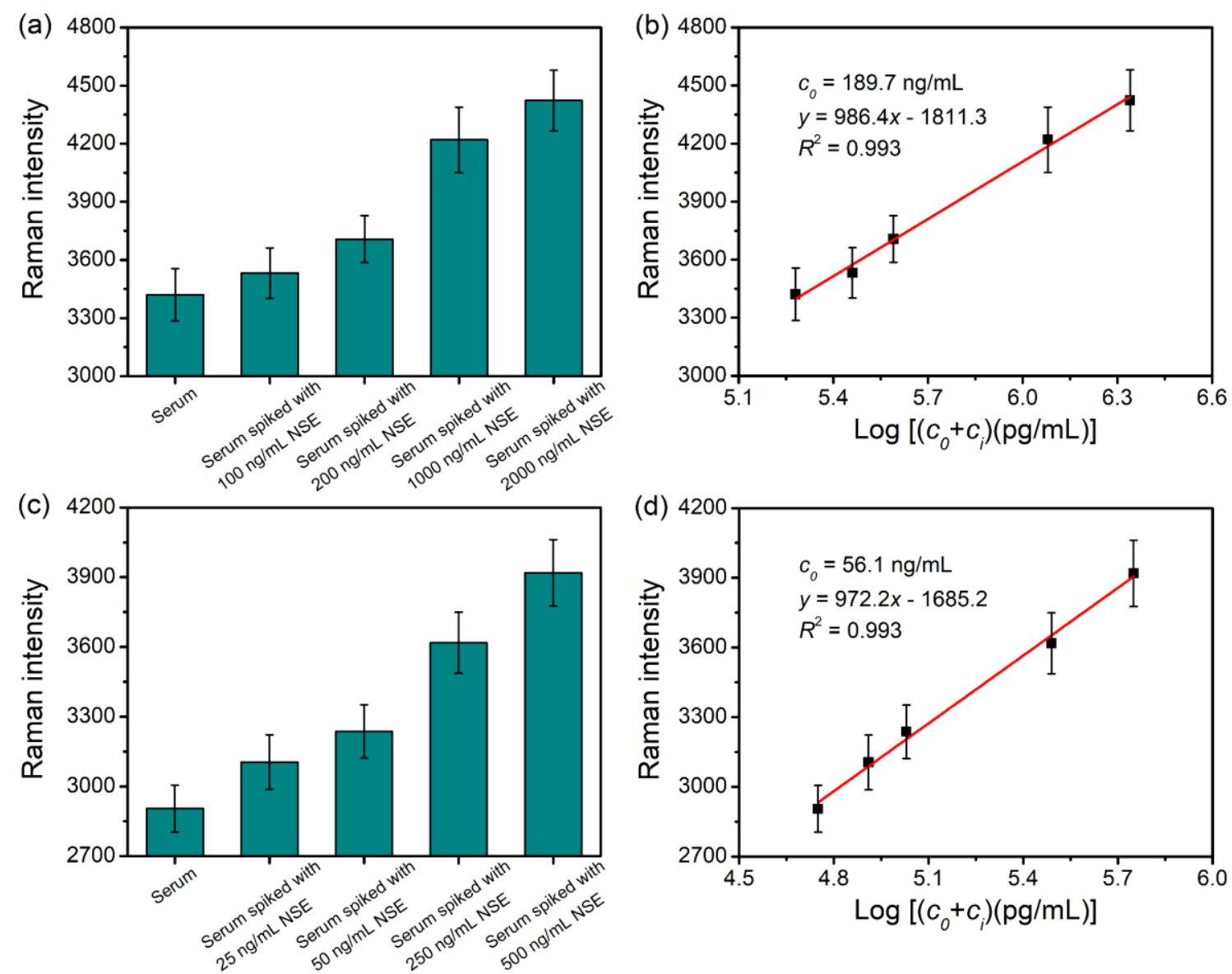

Figure S12. (a) Raman intensity for SCLC patient-1 serum spiked with different concentrations of NSE, (b) linear relationship between the Raman intensity and the logarithmic value of the total concentration of NSE in SCLC patient-1 serum sample $\left(\log \left[\left(c_{0}+c_{\mathrm{i}}\right)(\mathrm{pg} / \mathrm{mL})\right]\right)$, (c) Raman intensity for SCLC patient-2 serum spiked with different concentrations of NSE, and (d) linear relationship between the Raman intensity and the logarithmic value of the total concentration of NSE in SCLC patient-2 serum sample $\left(\log \left[\left(c_{0}+c_{\mathrm{i}}\right)(\mathrm{pg} / \mathrm{mL})\right]\right) . c_{0}$ was calculated according to the linear equation obtained with standard solutions by assumption that the matrix effect was eliminated by the duMIP-PISA. The error bars represent the standard deviation for three parallel experiments. 


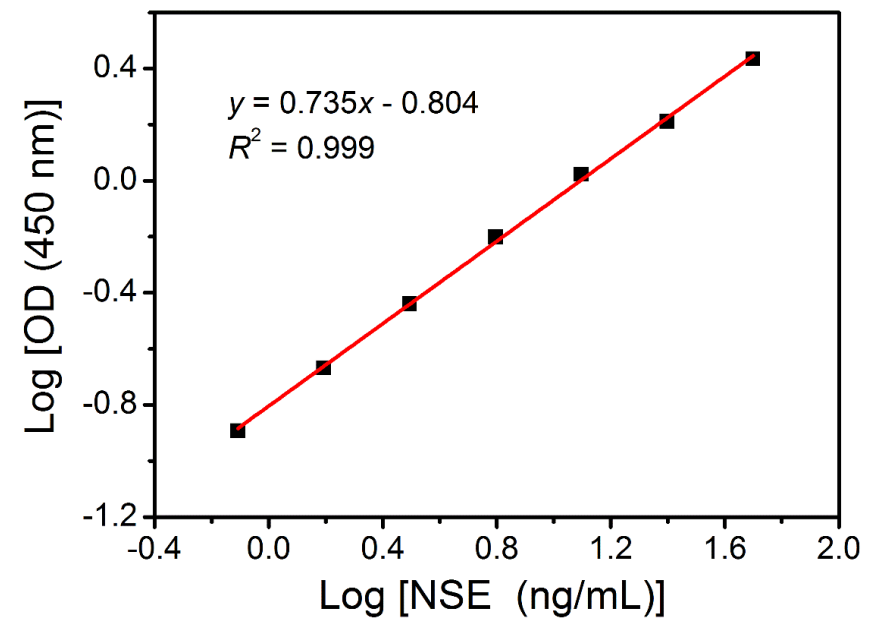

Figure S13. The linear relationship between the logarithm of OD at $450 \mathrm{~nm}$ and the logarithm of the NSE concentration in standard solution obtained with the commercial ELISA kit. 


\section{Supplementary Tables}

Table S1. The detailed information of identified peptides from C-terminal epitope of NSE and tryptic digests of HRP and BSA.

\begin{tabular}{|c|c|c|c|}
\hline Protein & $\mathrm{m} / \mathrm{z}$ & Sequence & Glycans \\
\hline NSE & 1083 & HNFRNPSVL & - \\
\hline \multirow[t]{10}{*}{ BSA } & 928 & YLYEIAR & - \\
\hline & 1016 & SHCIAEVEK & - \\
\hline & 1164 & LVNELTEFAK & - \\
\hline & 1306 & HLVDEPQNLIK & - \\
\hline & 1363 & SLHTLFGDELCK & - \\
\hline & 1440 & RHPEYAVSVLLR & - \\
\hline & 1480 & LGEYGFQNALIVR & - \\
\hline & 1568 & DAFLGSFLYEYSR & - \\
\hline & 1668 & MPCTEDYLSLILNR & - \\
\hline & 1824 & RPCFSALTPDETYVPK & - \\
\hline \multirow[t]{10}{*}{ HRP } & 743 & IAASILR & - \\
\hline & 803 & GFPVIDR & - \\
\hline & 903 & AAVESACPR & - \\
\hline & 959 & DTIVNELR & - \\
\hline & 2072 & DSFRNVGLN\#R & $\operatorname{Man}_{3} \mathrm{GlcNAc}_{2}$ \\
\hline & 3671 & GLIQSDQELFSSPN\#ATDTIPLVR & $\mathrm{XylMan}_{3} \mathrm{FucGlcNAc}_{2}$ \\
\hline & 3895 & LHFHDCFVNGCDASILLDN\#TTSFR & $\mathrm{XylMan}_{3} \mathrm{FucGlcNAc}_{2}$ \\
\hline & 4223 & QLTPTFYDNSC(AAVESACPR)PN\#VSNIVR & $\mathrm{XylMan}_{3} \mathrm{FucGlcNAc}_{2}$ \\
\hline & 4984 & LYN\#FSNTGLPDPTLN\#TTYLQTLR & $\mathrm{XylMan}_{3} \mathrm{FucGlcNAc}_{2}$ \\
\hline & & & $\mathrm{XylMan}_{3} \mathrm{FucGlcNAc}_{2}$ \\
\hline
\end{tabular}


Table S2. The detailed information of identified peptides from N-terminal epitope of NSE and tryptic digests of HRP and BSA.

\begin{tabular}{|c|c|c|c|}
\hline Protein & $\mathrm{m} / \mathrm{z}$ & Sequence & Glycans \\
\hline NSE & 1131 & SIEKIWARE & - \\
\hline \multirow[t]{11}{*}{ BSA } & 928 & YLYEIAR & - \\
\hline & 1016 & SHCIAEVEK & - \\
\hline & 1164 & LVNELTEFAK & - \\
\hline & 1306 & HLVDEPQNLIK & - \\
\hline & 1363 & SLHTLFGDELCK & $\longrightarrow$ \\
\hline & 1440 & RHPEYAVSVLLR & - \\
\hline & 1480 & LGEYGFQNALIVR & - \\
\hline & 1568 & DAFLGSFLYEYSR & - \\
\hline & 1640 & KVPQVSTPTLVEVSR & - \\
\hline & 1668 & MPCTEDYLSLILNR & - \\
\hline & 1824 & RPCFSALTPDETYVPK & - \\
\hline \multirow[t]{9}{*}{ HRP } & 803 & GFPVIDR & $\longrightarrow$ \\
\hline & 903 & AAVESACPR & - \\
\hline & 1587 & MGNITPLTGTQGQIR & - \\
\hline & 2072 & DSFRNVGLN\#R & $\operatorname{Man}_{3} \mathrm{GlcNAc}_{2}$ \\
\hline & 3671 & GLIQSDQELFSSPN\#ATDTIPLVR & $\mathrm{XylMan}_{3} \mathrm{FucGlcNAc}_{2}$ \\
\hline & 3895 & LHFHDCFVNGCDASILLDN\#TTSFR & $\mathrm{XylMan}_{3} \mathrm{FucGlcNAc}_{2}$ \\
\hline & 4223 & QLTPTFYDNSC(AAVESACPR)PN\#VSNIVR & $\mathrm{XylMan}_{3} \mathrm{FucGlcNAc}_{2}$ \\
\hline & \multirow{2}{*}{4984} & \multirow{2}{*}{ LYN\#FSNTGLPDPTLN\#TTYLQTLR } & $\mathrm{XylMan}_{3} \mathrm{FucGlcNAc}_{2}$ \\
\hline & & & $\mathrm{XylMan}_{3} \mathrm{FucGlcNAc}_{2}$ \\
\hline
\end{tabular}

